\title{
Oxygen Transport Ceramic Membranes
}

\section{Quarterly Report}

October- December 2001

\author{
By: \\ Dr. Sukumar Bandopadhyay \\ and \\ Dr. Nagendra Nagabhushana \\ School of Mineral Engineering \\ University of Alaska Fairbanks
}

Issued: January 2002

DOE Award \# DE-FC26-99FT400054

University of Alaska Fairbanks

School of Mineral Engineering

Duckering 355

Fairbanks, AK 99775 


\section{DISCLAIMER}

This report was prepared as an account of work sponsored by an agency of the United States Government. Neither the United States Government nor any agency thereof, nor any of their employees, makes any warrantee, express or implied, or assumes any legal liability or responsibility for the accuracy, completeness, or usefulness of any information, apparatus, product, or process disclosed, or represents that its use would not infringe privately owned rights. Reference herein to any specific commercial product, process, or service by trade name, trademark, manufacturer, or otherwise does not necessarily constitute or imply its endorsement, recommendation, or favoring by the United States Government or any agency thereof. The views and opinions of the authors expressed herein do not necessarily state or reflect those of the United States Government or any agency thereof. 


\section{Executive Summary}

Conversion of natural gas to liquid fuels and chemicals is a major goal for the Nation as it enters the $21^{\text {st }}$ Century. Technically robust and economically viable processes are needed to capture the value of the vast reserves of natural gas on Alaska's North Slope, and wean the Nation from dependence on foreign petroleum sources. Technologies that are emerging to fulfill this need are all based syngas as an intermediate. Syngas (a mixture of hydrogen and carbon monoxide) is a fundamental building block from which chemicals and fuels can be derived. Lower cost syngas translates directly into more costcompetitive fuels and chemicals.

The currently practiced commercial technology for making syngas is either steam methane reforming (SMR) or a two-step process involving cryogenic oxygen separation followed by natural gas partial oxidation (POX). These high-energy, capital-intensive processes do not always produce syngas at a cost that makes its derivatives competitive with current petroleum-based fuels and chemicals.

In the mid 80's BP invented a radically new technology concept that will have a major economic and energy efficiency impact on the conversion of natural gas to liquid fuels, hydrogen, and chemicals. ${ }^{1}$ This technology, called Electropox, integrates oxygen separation with the oxidation and steam reforming of natural gas into a single process to produce syngas with an economic advantage of 30 to 50 percent over conventional technologies. ${ }^{2}$

The Electropox process uses novel and proprietary solid metal oxide ceramic oxygen transport membranes [OTMs], which selectively conduct both oxide ions and electrons through their lattice structure at elevated temperatures. ${ }^{3}$ Under the influence of an oxygen

\footnotetext{
${ }^{1}$ Mazanec, T. J.; Cable, T. L.; Frye, J. G., Jr.; US 4,793,904, 27 Dec 1988, assigned to The Standard Oil Company (now BP America), Mazanec, T. J.; Cable, T. L.; US 4,802,958, 7 Feb 1989, assigned to the Standard Oil Co. (now BP America), Cable, T. L.; Mazanec, T. J.; Frye, J. G., Jr.; European Patent Application 0399833, 24 May 1990, published 28 November 1990.

${ }^{2}$ Bredesen, R.; Sogge, J.; "A Technical and Economic Assessment of Membrane Reactors for Hydrogen and Syngas Production" presented at Seminar on the Ecol. Applic. of Innovative Membrane Technology in the Chemical Industry", Cetraro, Calabria, Italy, 1-4 May 1996.

${ }^{3}$ Mazanec, T.J., Interface, 1996; Mazanec, T.J., Solid State Ionics, 70/71, 1994 11-19; "Electropox: BP's Novel Oxidation Technology", T.J. Mazanec, pp 212-225, in "The Role of Oxygen in Improving Chemical Processes", M. Fetizon and W.J. Thomas, eds, Royal Society of Chemistry, London, 1993; "Electropox:
} 
partial pressure gradient, oxygen ions move through the dense, nonporous membrane lattice at high rates with 100 percent selectivity. Transported oxygen reacts with natural gas on the fuel side of the ceramic membrane in the presence of a catalyst to produce syngas.

In 1997 BP entered into an OTM Alliance with Praxair, Amoco, Statoil and Sasol to advance the Electropox technology in an industrially sponsored development program. These five companies have been joined by Phillips Petroleum and now are carrying out a multi-year $\$ 40+$ million program to develop and commercialize the technology. The program targets materials, manufacturing and engineering development issues and culminates in the operation of semi-works and demonstration scale prototype units.

The Electropox process represents a truly revolutionary technology for conversion of natural gas to synthesis gas not only because it combines the three separate unit operations of oxygen separation, methane oxidation and methane steam reforming into a single step, but also because it employs a chemically active ceramic material in a fundamentally new way. On numerous fronts the commercialization of Electropox demands solutions to problems that have never before been accomplished. Basic problems in materials and catalysts, membrane fabrication, model development, and reactor engineering all need solutions to achieve commercial success.

Six important issues have been selected as needing understanding on a fundamental level at which the applied Alliance program cannot achieve the breadth and depth of understanding needed for rapid advancement. These issues include

1. Oxygen diffusion kinetics (University of Houston)

2. Grain structure and atomic segregation (University of Illinois - Chicago)

3. Phase stability and stress development (University of Missouri - Rolla)

4. Mechanical property evaluation in thermal and chemical stress fields (University of Alaska Fairbanks)

5. Graded ceramic/metal seals (Massachusetts Institute of Technology)

BP's Novel Oxidation Technology", T.J. Mazanec, pp 85-96, in "The Activation of Dioxygen and Homogeneous Catalytic Oxidation", D.H.R. Barton, A. E. Martell, D.T. Sawyer, eds, Plenum Press, New York, 1993; "Electrocatalytic Cells for Chemical Reaction", T.J. Mazanec, T.L. Cable, J.G. Frye, Jr.; Prep Petrol Div ACS, San Fran, 1992 37, 135-146; T.J. Mazanec, T.L. Cable, J.G. Frye, Jr.; Solid State Ionics, 1992, 53-56, 111-118. 
Statement of Work

Task 1 Design, fabricate and evaluate ceramic to metal seals based on graded ceramic powder / metal braze joints.

Task 2 Evaluate the effect of defect configuration on ceramic membrane conductivity and long term chemical and structural stability.

Task 3 Determine materials mechanical properties under conditions of high temperatures and reactive atmospheres.

Task 4 Evaluate phase stability and thermal expansion of candidate perovskite membranes and develop techniques to support these materials on porous metal structures.

Task 5 Assess the microstructure of membrane materials to evaluate the effects of vacancy-impurity association, defect clusters, and vacancy-dopant association on the membrane performance and stability.

Task 6 Measure kinetics of oxygen uptake and transport in ceramic membrane materials under commercially relevant conditions using isotope labeling techniques. 


\section{Task 1 \& 2 Development of Ceramic Membrane/Metal Joints}

Prof. Thomas W. Eagar, Dr Harold R Larson, Mr Raymundo Arroyave and Ms Jocelyn L. Wiese

All the tasks of the project has been completed in the previous quarter. A comprehensive summary of the accomplished tasks will be submitted in the final report.

\section{TASK 3: Determine material mechanical properties under conditions of high temperature and reactive atmosphere}

\section{Prof. Sukumar Bandopadhyay and Nagendra Nagabhushana University of Alaska Fairbanks}

Effect of Temperature, Pressure and Environment

In this quarter, the perovskite tubes 20573 (a-f) were evaluated for their strength as a function of temperature and pressure in $90 \% \mathrm{CO}_{2} / \mathrm{CO}$ environment. The average strengths (from 3 test) are plotted graphically in figure 1.

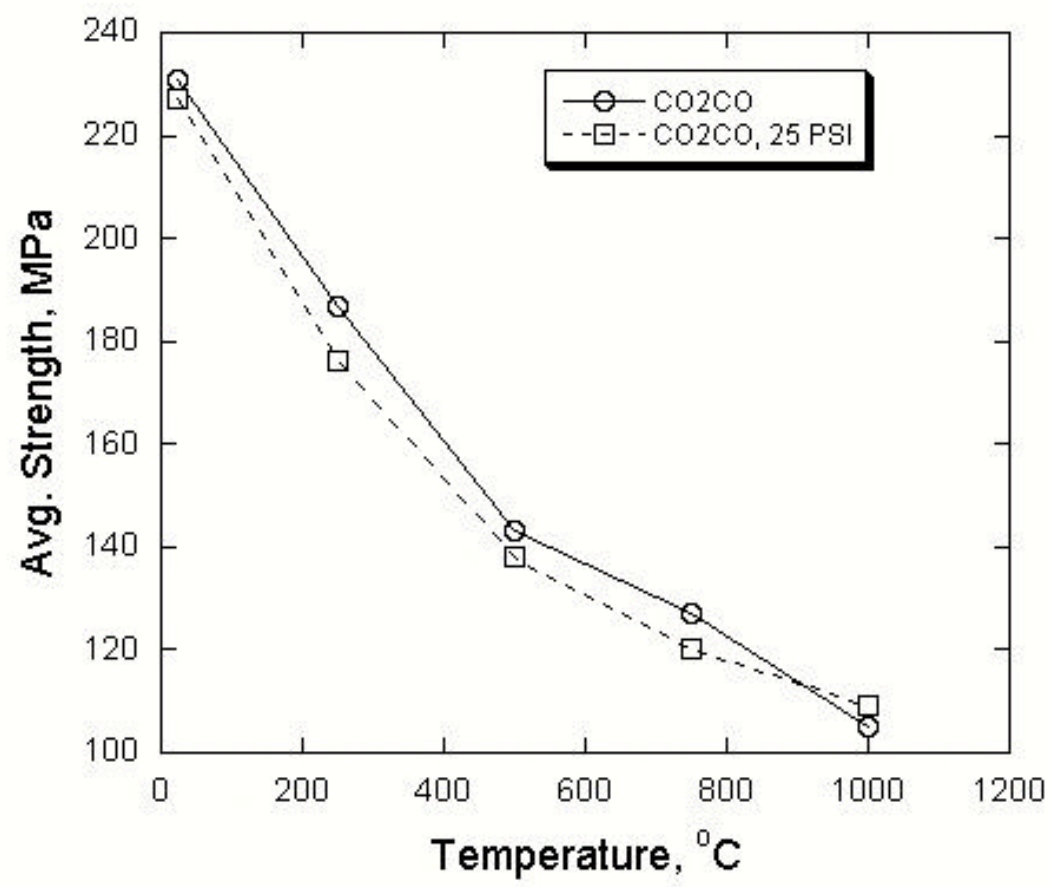

Fig. 1 Influence of temperature, and pressure on the fracture strength of perovskite tubes 
The perovskite tubes showed a similar decrease in fracture strength as reported earlier in air and in UHP nitrogen (with or without pressure). A big drop in strength value occurred up to $500^{\circ} \mathrm{C}$ and thereafter the rate of strength degradation was lowered. The strength degraded to nearly $50 \%$ of its value at room temperature in the same environment. With a chamber pressure of $25 \mathrm{PSI}(0.17 \mathrm{MPa})$, the strength of the tubes were consistently lower at all temperatures except at $1000^{\circ} \mathrm{C}$, where a slight increase was observed. Fracture at lower temperature in $90 \% \mathrm{CO}_{2} / 10 \% \mathrm{CO}$ did not show any dramatic changes in comparison with fracture in air and $\mathrm{N}_{2}$. Material degradation were observed to occur at $750^{\circ} \mathrm{C}$, but were markedly more severe at $1000^{\circ} \mathrm{C}$. Fracture and fracture morphology at $1000^{\circ} \mathrm{C}$ have been discussed in much detail in earlier sections.

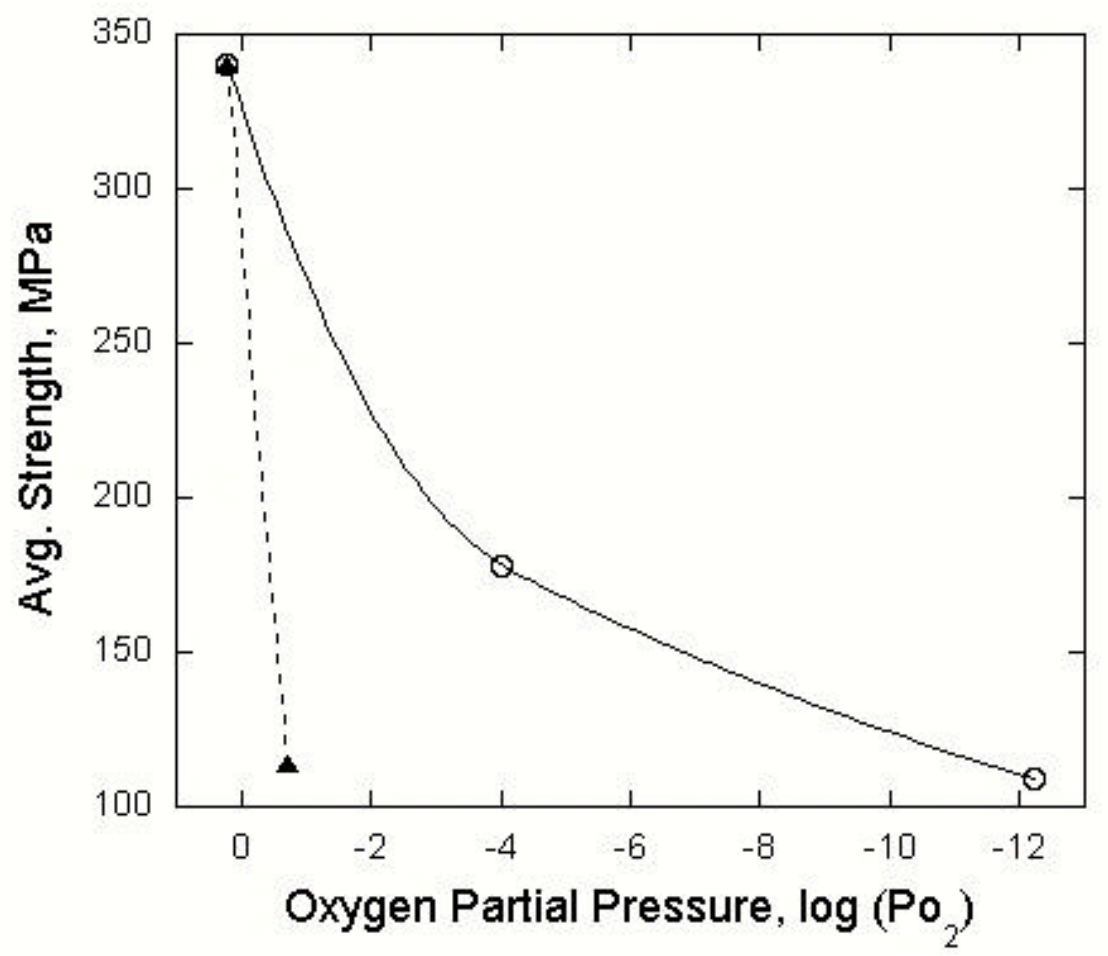

Figure 2: $\quad$ Effect of oxygen partial pressure on the strength of Perovskite tubes

As seen in figure 2, the strength of the perovskite tubes decrease with reducing partial pressure. The strength degradation is rapid at very low reducing conditions (air at $1000^{\circ} \mathrm{C}$ corresponds to $\left.\log \mathrm{Po}_{2}=-0.7\right)$. However, the strength degradation is less drastic in $\mathrm{N}_{2}$ and very high in $90 \% \mathrm{CO}_{2} / 10 \% \mathrm{CO}$. The strength degradation was examined by analyzing the outer surfaces exposed to the environment in a Seimens D5000 $\theta / \theta$ diffractometer using $\mathrm{Cu}$ radiation at $40 \mathrm{kv} / 30 \mathrm{ma}$ to determine any phases formed after the tests. The samples were tested in a parallel beam arrangement to minimize the displacement errors caused by the curved surfaces. The X-ray plots as shown in figure 3 (a-c) indicate that the perovskite is stable at all temperatures up to $750^{\circ} \mathrm{C}$ where after it decomposes forming additional phases such as $\mathrm{SrCrO}_{3}, \mathrm{SrFe}_{12} \mathrm{O}_{12}$ and $\mathrm{SrO}$. 


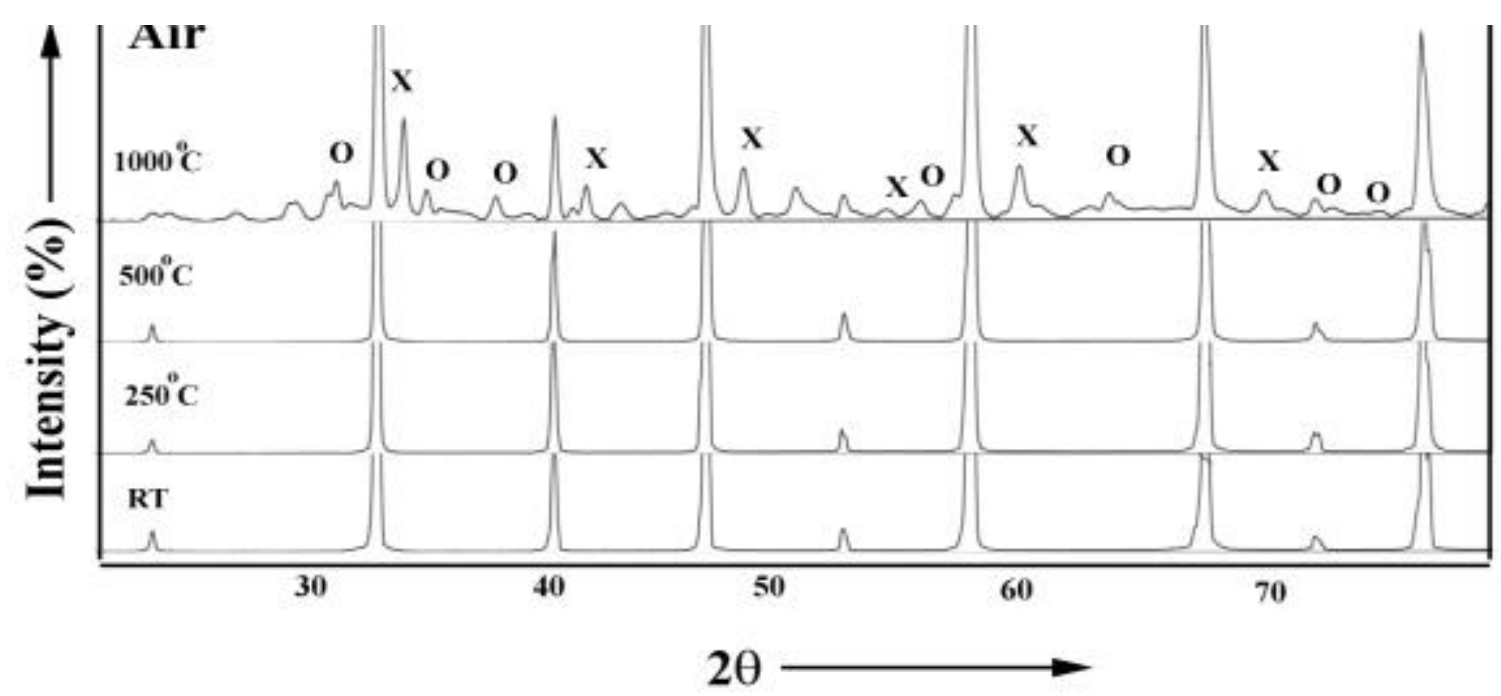

Figure 3 (a)

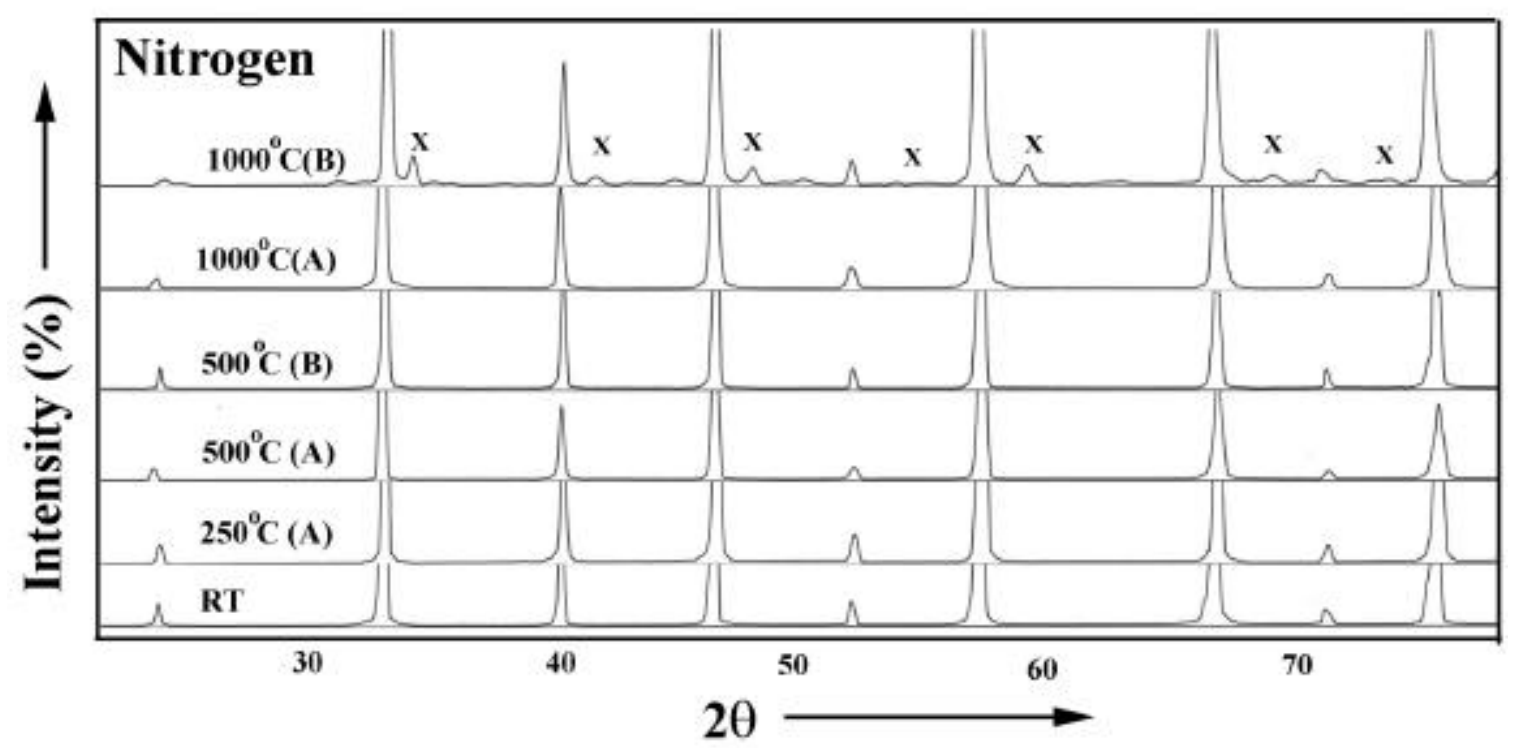

Figure $3(b)$

As seen from Figure $3 \mathrm{a}$ and $\mathrm{b}$, the perovskite is more stable in $\mathrm{N}_{2}$ as compared to in air. This corresponds well with the recorded loss of strength in air in comparison with $\mathrm{N}_{2}$. Similarly, the perovskite decomposes to a larger extent in $90 \% \mathrm{CO}_{2} / 10 \% \mathrm{CO}$ in comparison with $\mathrm{N}_{2}$ which explains the loss of strength in the environment. 


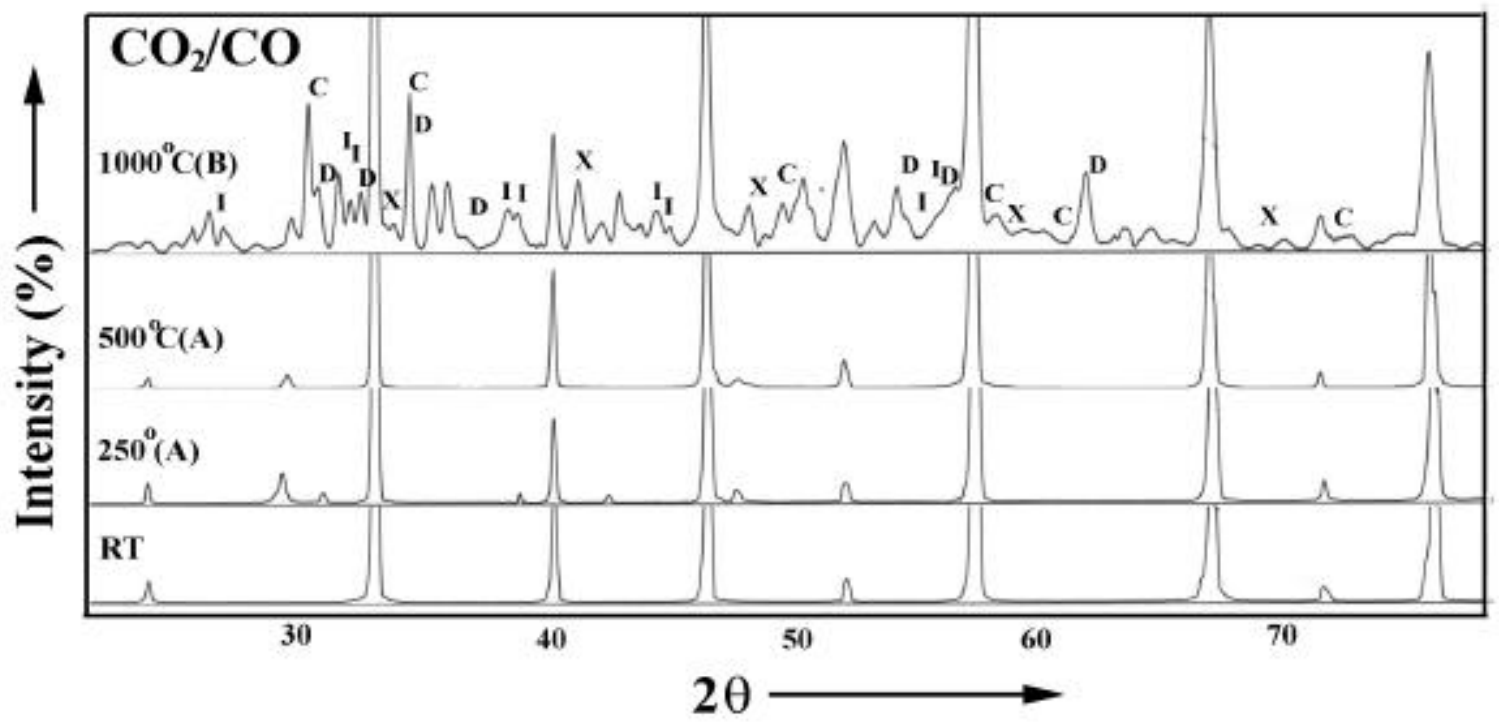

Figure 3(c)

Figure 3. X-ray plot of the Perovskites after exposure to the environment. The phases formed are: (X) $\mathrm{SrCrO}_{3} ;(\mathrm{O}) \mathrm{SrFe}_{12} \mathrm{O}_{12} ;(\mathrm{C}) \mathrm{SrO}$ and (D) $\mathrm{CrFeSr}_{2} \mathrm{O} 5.6$ 


\title{
Task 4: $\quad$ Preparation and Characterization of Dense Ceramic oxygen Permeable Membranes
}

\author{
By: Professor Harlan Anderson, University of Missouri-Rolla \\ Dr. Wayne Huebner, Dr. Xiao-Dong Zhou
}

All the tasks of the project has been completed in the previous quarter. A comprehensive summary of the accomplished tasks will be submitted in the final report

\section{Task 5: $\quad$ Measurement of Surface Activation/Reaction rates in lon Transport Membranes using Isotope Tracer and Transient Kinetic Techniques.}

\section{Prof. Alan Jacobson, University of Houston/University of Toronto}

All the tasks of the project has been completed in the previous quarter. A comprehensive summary of the accomplished tasks will be submitted in the final report 